\title{
Seal Lymphosarcoma
}

National Cancer Institute

\section{Source}

National Cancer Institute. Seal Lymphosarcoma. NCI Thesaurus. Code C135000.

Lymphosarcoma that occurs in a seal. 